\title{
The Effect of Medicaid Eligibility Expansions on Fertility ${ }^{*}$
}

\author{
Marianne P. Bitler \\ UC Irvine \\ Madeline Zavodny \\ Agnes Scott College
}

September 2009

CONTEXT: Pregnant women and children's eligibility for Medicaid was expanded dramatically during the 1980s and early 1990s. By lowering pregnancy and child health care costs, the Medicaid expansions may have increased fertility, leading to changes in birth and abortion rates.

METHODS: State-level natality and abortion data from 1982 to 1996 are used to estimate whether birth and abortion rates are related to the extent of states' Medicaid eligibility expansions and the fraction of women eligible for Medicaid, controlling for economic and demographic factors. Birth rates by race, marital status and education are examined as well as overall birth and abortion rates.

RESULTS: The Medicaid expansions are not significantly associated with a change in overall birth rates or abortion rates. Some results suggest a positive effect on birth rates among white women who have not completed high school. Restrictions on Medicaid funding of abortions decrease abortion rates and increase birth rates.

CONCLUSIONS: There is little evidence that expansions in public health insurance eligibility have sizable effects on women's fertility.

Contact author: Marianne Bitler, Department of Economics, 3151 Social Science Plaza, University of CaliforniaIrvine, Irvine, CA 92697; mbitler@uci.edu. The authors thank Jacob Klerman and Jonah Gelbach for helpful comments on previous versions of this paper. Bitler was affiliated with RAND and PPIC and Zavodny with Occidental College and the Federal Reserve Bank of Atlanta while part of this research was done. This paper is a substantially revised version of our 2000 Federal Reserve Bank of Atlanta Working Paper 2000-04. All errors and opinions are solely those of the authors. 


\section{The Effect of Medicaid Eligibility Expansions on Fertility}

Eligibility for Medicaid, the government health insurance program for low-income individuals, expanded dramatically for pregnant women and children during the 1980s and early 1990s. The goal of the expansions was to increase pregnant women's use of prenatal care and children's access to medical care. The proportion of women of childbearing age eligible for Medicaid coverage of pregnancy-related services more than doubled between 1987 and 1992, and the proportion of children eligible for full Medicaid coverage rose by at least 50\% (Cutler and Gruber 1996; Card and Shore-Sheppard 2004). Research has found that the expansions succeeded at increasing both prenatal care and children's medical care, resulting in better birth outcomes and lower child mortality (Currie and Grogger 2002; Currie and Gruber 1996a, 1996b). ${ }^{1}$ This article examines whether the Medicaid eligibility expansions had another, likely unintended effect: changing women’s fertility.

Understanding the effect of public health insurance on fertility is important for several reasons. Medicaid covers a sizable proportion of the population and involves substantial outlays. In 2007, for example, over $13 \%$ of the total population was covered by Medicaid, including over one in four children (U.S. Census Bureau 2008). Even more of the population is eligible but not currently enrolled in Medicaid. Total program outlays for fiscal year 2007 were over \$190 billion. Medicaid has covered over one-third of births in years since the 1990s expansions were completed (National Governors' Association 2005). The effect of the Medicaid expansions on fertility has implications for welfare reform, which further decoupled eligibility for governmentfunded health insurance from receipt of cash benefits. In addition, the expansion of governmentfinanced health insurance for children through the State Children’s Health Insurance Program 
(SCHIP) may have affected some women's fertility by lowering the cost of health insurance and care for current and future children.

There are several reasons why the Medicaid expansions may have led to higher birth rates. First, some women experienced a drop in the costs of prenatal care, delivery and child health care. ${ }^{2}$ This reduction in health care costs lowers the total cost of a child, which standard economic theory suggests should increase the number of children born. In addition, a reduction in health care costs effectively raises income (net of such costs), which in turn may increase births; most studies have concluded that increases in income that are not due to increases in women's earnings have a positive, albeit small, effect on fertility (Hotz, Klerman and Willis 1997; Macunovich 1996). For similar reasons, the expansions may have led to lower abortion rates if more women opted to give birth instead of terminating a pregnancy. Alternatively, the expansions could lead to no change in abortion rates if all extra births came from an expansioninduced increase in pregnancies.

It is also theoretically possible that the Medicaid expansions had a negative effect on birth rates. Research has found that, by decoupling eligibility for Medicaid from receipt of cash welfare benefits under the Aid to Families with Dependent Children (AFDC) program, the expansions may have caused an increase in women’s labor force participation (Yelowitz 1995). ${ }^{3}$ Higher labor force participation might have led to lower birth rates and, possibly, higher abortion rates. If the expansions improved child health outcomes, parents might have opted to have fewer

\footnotetext{
${ }^{1}$ Some studies have found that these results about health benefits of the expansions are not uniform across data sets or for all phases of the expansions (e.g., Dave, Decker, Kaestner and Simon 2008).

${ }^{2}$ In addition to reducing health care costs for women and children without health insurance, the expansions may have lowered costs for some individuals already covered by private health insurance. Some people appear to have switched from private insurance to Medicaid during the eligibility expansions (Cutler and Gruber 1996), although estimates of the magnitude of this "crowd-out" effect differ (see Card and Shore-Sheppard 2004). A pronatalist income effect also could have occurred through the extension of Medicaid coverage to older children and concomitant reduction in health care costs for those children.
} 
births in the classic "quality versus quantity” tradeoff (Becker 1960). This effect could also raise abortion rates (Joyce and Kaestner 1996). In addition, abortion rates might have risen because Medicaid covers abortion in some states, and the expansions reduced the cost of abortion for some women in those states. However, a decline in the cost of abortion also could increase sexual activity and the number of pregnancies, potentially raising both the birth rate and the abortion rate (Kane and Staiger 1996). Finally, it is possible that these changes would have no impact on birth or abortion rates if women potentially eligible for Medicaid-funded births or abortions were unaware of or did not respond to the law changes. Overall, these various theoretical arguments suggest we might see either an increase or decrease in birth rates, and similarly for abortion rates.

Most previous research suggested that expansions in Medicaid coverage lead to an increase in births and drop in abortions. Studies using samples from natality data or the Current Population Survey found increases in birth rates of $3 \%$ to $5 \%$ as a result of the Medicaid expansions that occurred during the late 1980s and 1990s (Joyce, Kaestner and Kwan 1998; Yelowitz 1994; Baughman 2001). ${ }^{4}$ Medicaid coverage of abortions—which the expansions included in some states — was found to be negatively associated with birth rates, particularly among black, unmarried and less-educated women (Klerman 1999). Studies that used abortion data from selected states found that the Medicaid expansions reduced abortions among unmarried nonblacks but had no effect among unmarried blacks (Joyce and Kaestner 1996; Joyce, Kaestner and Kwan 1998). More generally, restrictions on Medicaid funding of abortions

\footnotetext{
${ }^{3}$ However, Ham and Shore-Sheppard (2003) did not find evidence of a significant increase in women's labor force participation.

${ }^{4}$ Research on health insurance coverage and births also suggested a positive effect. In the RAND Health Insurance Experiment conducted during the 1980s, women randomly assigned to receive free medical care for three to five years had 29\% more births than women assigned to cost-sharing medical plans (Leibowitz 1990). This finding is not clear evidence of increased fertility, however, because the participants knew that the experiment would only run
} 
were found to be negatively associated with abortion rates (e.g., Blank, George and London 1996; Haas-Wilson 1993).

However, a recent paper that used methods similar to those here but focused on a slightly later time period concluded that the expansions did not have a discernable effect on fertility for most groups (DeLeire, Lopoo and Simon 2007). Our findings are generally compatible with that research; we also find no significant effect of the expansions on birth rates over a longer time period that covers more phases of the expansions.

This article adds to the existing research on Medicaid eligibility and fertility in several ways. First, we use the same framework to estimate whether birth and abortion rates are related to the fraction of women eligible for Medicaid if they became pregnant and to the expansionrelated income eligibility threshold for Medicaid. Our measure of the fraction of women eligible uses a national sample of women but each state's eligibility rules to avoid possible endogeneity of state-level eligibility, as advocated by Currie and Gruber (1996a). As discussed below, this approach offers several advantages over previous published research that used other measures of the extent of the expansions. Another contribution of our study is that we control for the impact of several other important factors, such as economic conditions, welfare generosity and whether a state restricted Medicaid funding of abortions.

A further contribution is that this study includes more years and states than most previous research and analyzes the full effect of the expansions. We investigate the time period 19821996, which includes several pre-expansion years and the more limited expansions that took place during the mid-1980s as well as the later broader expansions. Most previous studies of the fertility effects of the expansion focused on the broadly targeted phases and did not include any

for several years; these women may only have altered the timing of births and not their total number of births (the Medicaid expansions, in contrast, are permanent unless the law is changed). 
pre-expansion years, thus capturing the impact of moving from the narrow phase of the expansions to the broad phase but not the full effect of the expansions. The early phases of the expansion had considerably larger effects on children's Medicaid coverage than did the later phases (Card and Shore-Sheppard 2004) and may have also had a large impact on fertility. Whereas some previous research that used natality and abortion data to study the impact of the expansions examined only selected groups of states, this study includes all states.

To preview our results, we find little evidence that the Medicaid expansions increased overall birth rates. Some results do point to a positive fertility effect among high school dropout white women when controlling for the eligibility threshold, but this finding is not robust to instead controlling for the share of women only made eligible because of the expansion. Changes in abortion rates are not related to the Medicaid expansions. State-level restrictions on Medicaid funding of abortions are associated with lower abortion rates overall and with higher birth rates among unmarried black women and black women with a high school degree but no college.

\section{CHRONOLOGY OF MEDICAID EXPANSIONS}

Until the mid-1980s, Medicaid coverage was tightly linked to receipt of AFDC benefits, which effectively limited eligibility to female-headed households with children and with income low enough to qualify for AFDC. In states that opted to have an AFDC-Unemployed Parent (AFDC-UP) program, two-parent households that met the income requirements qualified for Medicaid. ${ }^{5}$ Beginning in 1984, a series of laws expanded pregnant women and children's eligibility for Medicaid coverage. Table 1 summarizes the eligibility expansions.

\footnotetext{
${ }^{5}$ States were required to have an AFDC-UP program by October 1990; before then, the program was optional. AFDC-UP allowed two-parent families to receive AFDC benefits if the primary earner was working less than 100
} 
During the early, narrowly targeted phase of the expansion (which was in effect from October 1984 through March of 1987), states were required to extend Medicaid coverage to several groups that did not meet the family structure requirements of the AFDC program. ${ }^{6}$ During this first phase of the expansion, Medicaid recipients still had to meet the AFDC resource requirements, which required income to be well below the poverty level in most states. ${ }^{7}$ The overall fraction of women aged 15-44 eligible for Medicaid rose less than 5 percentage points during the narrowly targeted phase of the expansion (Currie and Gruber 1996a), although increases were larger among some subgroups.

Beginning in April 1987, states were given the option and then later required to extend Medicaid coverage to pregnant women and children in families with incomes substantially above the AFDC resource limits in most states, regardless of family structure. States were required to extend coverage by July 1989 to all pregnant women with family incomes below $75 \%$ of the federal poverty line, and to $133 \%$ by April 1990. Eligibility rates among women aged 15-44 more than doubled during this broad phase of the expansion (Currie and Gruber 1996a).

States differed in the timing and extent of Medicaid eligibility expansions. In September 1984, for example, 23 states and the District of Columbia had AFDC-UP programs in place and offered Medicaid benefits to pregnant married women who met the program's resource requirements. One of the narrowly targeted expansions required the remaining 27 states to offer Medicaid coverage by October 1984 to pregnant women who had a spouse present in the household and who met their state's AFDC resource requirements. There also was variation

hours per month and met the program's work history requirement in addition to the family meeting the other AFDC program rules.

${ }^{6}$ States had the option of using their own funds to extend coverage beyond groups eligible under the federal law.

${ }^{7}$ In addition to the expansions listed in Table 1, Medicaid eligibility was extended to older children in families with incomes below the AFDC cutoff, regardless of family structure ("Ribicoff children"), and to medically needy pregnant women (women with incomes above the AFDC cutoff but with medical expenses that brought net income below the AFDC cutoff) during the first phase of the expansions. 
across states in the timing of the broad eligibility expansions; as of February 1996, for example, 28 states had opted to cover pregnant women with incomes of $185 \%$ of the federal poverty level or higher, while the remaining states at least met the minimum level of $133 \%$. This study uses this variation across states in the timing and extent of expansions to estimate the effect of Medicaid eligibility threshold expansions on fertility.

Figure 1 shows the average income threshold for Medicaid eligibility relative to the federal poverty level during 1982-1996. ${ }^{8}$ The figure displays both the expansion-related threshold (after the expansions began in late 1984) and the eligibility threshold for Medicaid coverage via the AFDC program; both are shown relative to the federal poverty level for a family of three. The average AFDC-related threshold declined slightly during the 1990s whereas the average expansion-related threshold rose steadily during the mid-1980s and then plateaued during the 1990s at over three times the AFDC income limit.

The figures also show the estimated fraction of women eligible for expansion-related Medicaid benefits if they became pregnant. ${ }^{9}$ Separate fractions are shown for white and black women to reflect the large differences in eligibility rates, with blacks much more likely than whites to become eligible for expansion-related Medicaid coverage. The figure also shows that the estimated expansion-related eligibility rates track the rise in the Medicaid expansion threshold.

Pregnant women are covered under the expansions only for services related to the pregnancy. In some states, pregnant women's coverage includes abortion services. States have

\footnotetext{
${ }^{8}$ The average threshold is created by weighting state thresholds by the population of women aged 15-44 in the state.

${ }^{9}$ The estimates are constructed from the 1983-1997 March Current Population Surveys (CPS). The March CPS asks about income during the last calendar year and contemporaneous family structure. Using each state's eligibility rules, we calculated the fraction of women in the CPS each year who were eligible for expansion-related Medicaid based on their family (or subfamily) income during the last calendar year and their family structure as of March; women who were eligible via the AFDC program were not included in this fraction.
} 
the option to cover abortions in their Medicaid program but do not receive federal matching funds for most abortions. In almost all states with Medicaid programs that cover abortions, women eligible for Medicaid under the expansions are also eligible for Medicaid-covered abortions (Sollom 1995).

\section{DATA}

\section{Birth rates}

This analysis uses data from national birth certificate data sets created by the National Center for Health Statistics (NCHS). The sample consists of all live births between 1982 and 1996 to women aged 15 to 44 residing in the 50 states and the District of Columbia whose age, race and marital status were reported. The sample ends in 1996 to minimize confounding the effects of the Medicaid expansions and welfare reform and other policy changes which might impact fertility and abortions, such as the creation of the State Children's Health Insurance Program. ${ }^{10}$ In analysis using data for women who did not complete high school, 4 states with very incomplete reporting of education during several years are dropped from the sample. ${ }^{11}$ We use quarterly birth rates created by dividing the number of births to women in a given quarter by the population (in thousands).

\footnotetext{
${ }^{10}$ Some states had waivers from the traditional AFDC program prior to national welfare reform, which began with the passage of the Personal Responsibility and Work Opportunity Reconciliation Act (PRWORA) in August 1996 and replaced AFDC with Temporary Assistance for Needy Families (TANF). Controlling for whether a state has a family cap in place does not affect the results; estimates of the relationship between birth rates and the family cap are mixed. Controlling for waivers and family caps also does not affect the results; waivers tend to be negatively associated with birth rates, and family caps are positively associated with birth rates. We do not examine the effect of the Child Health Insurance Program (CHIP), a major expansion of Medicaid for children that began in 1997; Baughman (2001) includes the CHIP program in her analysis.

${ }^{11}$ Education data are incomplete for California, New York, Texas and Washington. In states that did not record marital status on birth certificates (California, Connecticut, Michigan, Nevada, New York and Texas), NCHS imputed the mother's marital status, and we use these imputed data. Our results are robust to omitting these states with imputed marital status. For states and years when the detail natality data include only one-half of births, we
} 
This analysis distinguishes between whites and blacks; nonwhites/nonblacks ("other race") are not included here because of the relatively small sample sizes in most states. ${ }^{12}$ The data are stratified by race because previous research indicated that the determinants of fertility behavior differ for whites and blacks (Levine et al. 1999). In particular, the effect of the expansions may differ because blacks are poorer, on average, and therefore more likely to meet the income threshold (as shown in Figure 1). However, blacks are more likely to already be eligible for Medicaid before the expansions via the AFDC program. White women's fertility may be more affected by the expansions because they are less likely than blacks to qualify for Medicaid via the AFDC program.

We examine the relationship between Medicaid expansions and fertility by marital status or education within racial groups. The responsiveness of women's fertility to Medicaid eligibility may differ by marital status and education because less educated and single women tend to have fewer financial resources than more educated and married women and therefore are more likely to be eligible for Medicaid via the expansions. The expansions therefore may have had larger effects on less educated and unmarried women's fertility.

We focus here on birth and abortion rates relative to the number of women aged 15-44 in a given group. We use the Census Bureau's annual state-level counts of the number of women aged 15-44 by race. To calculate denominators by marital status or education, we multiply those counts by the distribution of women aged 15-44 across marital status and education groups in that state and year from the March CPS. The birth rate among unmarried white women aged 1544, for example, is the number of births to unmarried white women aged 15-44 in the natality 
data divided by the number of unmarried white women aged 15-44, calculated by multiplying the Census Bureau's count of the number of white women aged 15-44 times the fraction of white women aged 15-44 who are married in the CPS. ${ }^{13}$

A primary advantage of using the natality data is that they are a near census of births in the U.S. and thus should not suffer from significant underreporting of births. The 1990 Census, for example, may have missed up to $20 \%$ of infants compared with the natality data (Daponte and Haviland 2001). However, the natality data have one significant disadvantage: because the data only include births, they contain no information on women who are pregnant but do not give birth. This motivates our analysis of abortion rates.

\footnotetext{
${ }^{12}$ We do not distinguish between Hispanics and non-Hispanics because Hispanic origin is not reported for a substantial fraction of births in some years (42\% in 1981, for example). Reporting of Hispanic origin first reached over $70 \%$ in 1989.

${ }^{13}$ Young women who have not yet completed high school are categorized as not having completed high school in this analysis even though many of them are likely to finish high school. If a state has a disproportionately young population, it will appear to have a disproportionately large number of women who have not completed high school. The regressions control for the age distribution of each state's population across 5-year age groups in order to control for this.
} 


\section{Abortion rates}

This analysis uses two sources of annual data on the number of abortions: the Centers for Disease Control (CDC) and the Alan Guttmacher Institute (AGI). The CDC data are based on reports from state public health agencies, but the data are incomplete in states in which not all providers provide reports to the public health agency. The AGI data are based on surveys of all known abortion providers and consistently include more abortions than the CDC data, although the ratio of the two counts varies over time. The AGI data are not available for 1983, 1986, 1989, 1990, 1993 and 1994, so we present estimates using the CDC data for the nine years during the period 1982-1996 when AGI data are available as well as for the period as a whole.

We do not examine the effect of the expansions on abortion rates by race, education or marital status. The CDC reports abortion counts for some demographic groups, such as by race, but the data are only available for a subsample of states and years and their accuracy is uncertain. We use abortion rates calculated by dividing the reported number of abortions in each state and year by the population of women aged 15-44.

\section{METHODS}

We use OLS panel data techniques to estimate the relationship between Medicaid eligibility and fertility. We regress the natural logarithm of the birth rate or the abortion rate on the expansion-related fraction of women eligible for Medicaid or on the expansion-related income threshold for Medicaid eligibility, expressed as a fraction of the poverty line. All regressions also include economic and demographic variables (described below), state and time fixed effects, and state-specific linear time trends. 
The regressions include the unemployment rate and the natural log of real income per capita to control for economic conditions that may affect fertility. The natural log of the real maximum AFDC benefit for a family of three is included to control for any effect of welfare benefits on fertility. The regressions also include the natural log of the real combined maximum value of federal and state earned income tax credits (EITC) for a taxpayer with 1 qualifying child. $^{14}$

Because Medicaid funding of abortions may affect abortion and birth rates (e.g., Klerman 1996; Klerman 1999), the regressions also include a dummy variable that indicates whether a state restricts Medicaid funding of abortions. In the birth rate regressions, the abortion-funding variable is measured one quarter after conception to reflect Medicaid financing of abortions toward the end of the first trimester of a pregnancy; in the abortion rate regressions, the variable is the contemporaneous annual average.

The regressions also control for the distribution of women across 5-year age groups. Observations were weighted using the population size. The standard errors Huber-White corrected for heteroscedasticity and clustered at the state level to allow for arbitrary correlation within state. There are a maximum of 3060 observations in the birth rate regressions (2820 in the ones stratified by education since 4 states are not included) and 765 observations in the full sample CDC abortion rate regressions (459 in the AGI and restricted sample CDC ones). The sample sizes for the black birth rate regressions are somewhat smaller, as some state-year cells are missing women in some groups.

Most previous research on the fertility effects of the expansions used indicator variables to measure the extent of the expansions (e.g., Joyce and Kaestner 1996; Joyce, Kaestner and

\footnotetext{
14 These variables are measured contemporaneously, but the findings are very similar in magnitude and significance if we instead control for the variables as measured during the time of conception.
} 
Kwan 1998). This study, in contrast, uses continuous variables: the income eligibility threshold and the fraction of women eligible. We believe these discrete variables are a better measure of the extent of the expansions than dummy variables indicating whether a state has expanded eligibility to, for example, 100 or $133 \%$ of the federal poverty level, for example. We use two measures because each of our variables is imperfect. The income eligibility threshold does not reflect state heterogeneity in actual income levels and hence eligibility, while the fraction eligible - which is constructed with a national sample of women but using each state's eligibility rules following Currie and Gruber (1996a)—is measured with error. ${ }^{15}$ Neither variable measures actual state-level eligibility, or take-up, which would be endogenous since most women’s eligibility under the expansions depends on their becoming pregnant (e.g., Currie and Gruber, 1996a).

\section{RESULTS}

\section{Birth rate results}

The results indicate that the Medicaid expansions had little effect on birth rates among women aged 15-44 overall. As the first column in Table 2 reports, a 100 percentage point increase in the expansion-related eligibility threshold (measured as a proportion of the federal poverty line) is associated with a significant $0.9 \%$ increase in the birth rate among white women

\footnotetext{
${ }^{15}$ We applied state-level rules to a national sample of women aged 15-44 in the CPS to create these estimates because of concerns that the characteristics of state-level populations, such as the fraction married or who already have children, might be endogenous to state level policies. This possible endogeneity arises from the fact that the fraction of women eligible in a specific state depends on that state's economic and demographic characteristics, which may in turn be associated with fertility behavior (Currie and Gruber 1996a). Although using the national sample reduces such endogeneity bias, it creates measurement error. In addition, the structure of the CPS leads to measurement error. We applied contemporaneous eligibility rules to women's family structure as of March and income during the last calendar year, which creates measurement error for women whose financial situations have changed. Using annual eligibility shares in the quarterly births regressions also leads to measurement error.

Further, we cannot fully account in the CPS data for the income disregards used to determine Medicaid eligibility,
} 
aged 15-44. Evaluated at the mean expansion-related eligibility threshold (conditional on expansion) of $158 \%$, this estimate implies that the expansions led to a $1.4 \%$ increase in the birth rate among white women overall. However, the corresponding result for black women is $0.5 \%$ but is not statistically significant at the $5 \%$ level. If we instead measure the extent of the expansions using the fraction of women eligible for expansion-related Medicaid, we do not find a significant relationship between birth rates and the expansions for either whites or blacks (Table 3, column 1).

Once we examine birth rates by marital status, there is little evidence of any significant effect of the expansions on fertility. As column 2 of Table 2 shows, a 100 percentage point increase in the expansion-related eligibility threshold is associated with a $2.7 \%$ increase in the birth rate among unmarried white women and a 3.3\% increase for unmarried black women, but neither is significant at the $5 \%$ level. The results for the estimated fraction of women eligible for expansion-related Medicaid also indicate no statistically significant effects among unmarried women (Table 3, column 2). For married women, the eligibility threshold is not significantly related to birth rates for either racial group or either specification for the policy change (Table 2, column 3 and Table 3, column 3).

The effect of the Medicaid eligibility expansions appears to differ somewhat across education groups, although only one of the 12 coefficients is statistically significant. One of four results for women who have not completed high school indicate a significant positive relationship, and the estimated magnitude is relatively large (column 4 of Tables 2 and 3). The results for whites indicate that a 100 percentage point increase in the eligibility threshold would result in a $7.7 \%$ increase in the birth rate, which is statistically significant at the $5 \%$ level.

and cannot measure assets at all. Finally, the CPS undersamples very poor women, whose fertility may be quite responsive to the Medicaid expansions. 
However, the corresponding coefficient for the effect when the policy is modeled by the increase in the share of women eligible is not significant. For women who have a high school but not college education, all four coefficients are negative but none are significant (column 5). Neither measure of the extent of the expansions is significantly associated with birth rates among women who have attended college (column 6).

There are several significant relationships between birth rates and the other covariates reported in Tables 2 and 3. In general, birth rates are positively associated with the log of real AFDC benefits for some groups of blacks. Birth rates among whites tend to be positively associated with the log of real income per capita as are birth rates for unmarried blacks. There is generally no significant relationship between birth rates and the unemployment rate or the log of real EITC benefits. Confirming some existing research, the results indicate a positive relationship between birth rates and state restrictions on Medicaid funding for abortions for some groups, particularly unmarried black women and black women with high school degrees who have not attended college.

\section{Abortion rate results}

The Medicaid eligibility expansions do not appear to have affected overall abortion rates. As the results in Table 4 show, abortion rates are not significantly associated with either the eligibility threshold (top panel) or the fraction of women eligible for Medicaid as a result of the expansions (bottom panel). This result holds for the CDC data, the AGI data, and the CDC data restricted to years with AGI data available.

Some other factors do appear to influence abortion rates. In the CDC data, abortion rates are generally positively associated with the log of real average income; these results do not hold 
in the AGI data, however. Both data sources indicate that abortion rates are significantly lower when states restrict Medicaid funding for abortions.

\section{DISCUSSION}

Beginning in 1984, the eligibility of pregnant women and children for Medicaid increased dramatically. Eligible pregnant women were covered for prenatal care, delivery and postpartum care, while eligible children received full Medicaid benefits. The expansions lowered the cost of health care for families who met the new income limits and were previously uninsured and may have also lowered health care costs for some individuals with private insurance. This study examined whether this reduction in health care costs led to changes in fertility behavior.

Like other recent work (DeLeire, Lopoo and Simon, 2007), our results do not indicate a significant positive relationship between birth rates or abortion rates and the Medicaid eligibility expansions overall. Some results do point to a positive fertility effect among white women who have not completed high school. However, the births rates for all other groups of black and white women are not significantly related to the extent of the expansions, regardless of whether we measure the extent of the expansions using the eligibility threshold or the share of women made eligible via the expansions. There is also no evidence that the Medicaid expansions had a significant effect on abortion rates overall. Like existing research, we find that Medicaid restrictions on the funding of abortions are related to higher birth rates and lower abortion rates for some groups.

One important caveat to these results is that the Medicaid expansions may not have increased the total number of births in those groups that do appear to be affected but rather 
simply shifted some births to younger ages. Because the data used here only cover the period 1982 to 1996, the observed increase in birth rates for some groups could be due to changes in timing but not a long run increase in the total number of births. These questions cannot be fully examined using the natality data, which only report the interval since the last live birth and last did so in 1994, nor in the Current Population Survey, which last asked about complete fertility histories in 1995. Future research could use data sources with more complete fertility histories to further examine this issue. 


\section{REFERENCES}

Baughman, R., 2001. Medicaid, CHIP and fertility: Does expanding public health insurance encourage births? Unpublished PhD dissertation, Syracuse University.

Becker, G., 1960. An economic analysis of fertility. In: Demographic and Economic Change in Developed Countries. Princeton, NJ: NBER, pp. 209-231.

Blank, R., George, C., and London, R., 1996. State abortion rates: The impact of policies, providers, politics, demographics, and economic environment. Journal of Health Economics 15, 513-553.

Card, D., and Shore-Sheppard, L.D., 2004. Using discontinuous eligibility rules to identify the effects of the federal Medicaid expansions. Review of Economics and Statistics 86, 752-766.

Currie, J., and Grogger, J., 2002. Medicaid expansions and welfare contractions: Offsetting effects on prenatal care and infant health? Journal of Health Economics 21, 313-335.

Currie, J., and Gruber, J., 1996a. Saving babies: The efficacy and cost of recent changes in the Medicaid eligibility of pregnant women. Journal of Political Economy 104, 1263-1296.

Currie, J., and Gruber, J., 1996b. Health insurance eligibility, utilization of medical care, and child health. Quarterly Journal of Economics 111, 431-466.

Cutler, D.M., and Gruber, J., 1996. Does public insurance crowd out private insurance? Quarterly Journal of Economics 111, 391-430.

Daponte, B.O., and Haviland, A.M., 2001. An examination of the quality of 1990 Census data on the U.S. child population: Comparing Census data with data from administrative records. H. John Heinz III School of Public Policy and Management, Mimeo.

Dave, D., Decker, S., Kaestner, R., and Simon, K., 2008. Re-examining the effects of Medicaid expansions for pregnant women. NBER Working Paper 14591.

DeLeire, T., Lopoo, L.M., and Simon, K.I. 2007. Medicaid expansions and fertility in the United States. NBER Working Paper No. 12907.

Haas-Wilson, D., 1993. The economic impact of state restrictions on abortion: Parental consent and notification laws and Medicaid funding restrictions. Journal of Policy Analysis and Management 12, 498-511.

Ham, J.C., and Shore-Sheppard, L.D. 2003. Did expanding Medicaid affect welfare participation? NBER Working Paper 9803. 
Hotz, V.J., Klerman, J.A., and Willis, R.J., 1997. The economics of fertility in developed countries. Pp. 275-347 in Handbook of Population and Family Economics, vol. 1A, edited by M.R. Rosenzweig and O. Stark. Amsterdam: North-Holland.

Joyce, T., and Kaestner, R., 1996. The effect of expansions in Medicaid income eligibility on abortion. Demography 33, 181-192.

Joyce, T., Kaestner, R., and Kwan, F., 1998. Is Medicaid pronatalist? The effect of eligibility expansions on abortions and births. Family Planning Perspectives 30, 108-113.

Kane, T.J., and Staiger, D., 1996. Teen motherhood and abortion access. Quarterly Journal of Economics 111, 467-506.

Klerman, J.A., 1996. Fertility effects of Medicaid funding of abortions: A disaggregated analysis. RAND, Mimeo.

Klerman, J.A., 1999. U.S. abortion policy and fertility. AEA Papers and Proceedings 89:261264.

Leibowitz, A., 1990. The response of births to changes in health insurance costs. Journal of Human Resources 25, 697-711.

Levine, P.B., Staiger, D., Kane, T.J., and Zimmerman, D.J. 1999. Roe v Wade and American fertility. American Journal of Public Health. 89, 199-203.

Macunovich, D.J., 1996. A review of recent developments in the economics of fertility. Pp. 91150 in Household and Family Economics, edited by P.L. Menchik. Boston: Kluwer.

National Governors' Association, 2005. State Coverage of Pregnant Women and Children. MCH Update.

Sollom, T., 1995. State Actions on Reproductive Health Issues in 1994. Family Planning Perspectives 27, 83-87.

U.S. Census Bureau, 2008. Income, Poverty, and Health Insurance Coverage in the United States, 2007. Current Population Reports, P60-235, U.S. Government Printing Office, Washington, DC.

Yelowitz, A.S., 1994. Is health care coverage a pro-natal policy? Unpublished PhD dissertation, MIT.

Yelowitz, A.S., 1995. The Medicaid notch, labor supply, and welfare participation: Evidence from eligibility expansions. Quarterly Journal of Economics 110, 909-939. 
Table 1. Summary of Medicaid Program Expansions Affecting Pregnant Women and Children

Narrowly targeted expansions:

Effective October 1984, states required to cover first-time pregnant women if they would be eligible for AFDC if their children were already born; states without AFDC-UP programs required to cover married pregnant women if they met AFDC program resource guidelines.

Effective July 1986, states required to cover pregnant women regardless of family structure if they met AFDC program resource guidelines.

Broad expansions:

Beginning April 1987, states allowed to cover pregnant women and children under age 2 with incomes up to $100 \%$ of federal poverty line.

Beginning July 1988, states allowed to cover pregnant women and children under age 2 up to $185 \%$ of poverty line and children under age 5 up to $100 \%$.

Beginning October 1988, states allowed to cover children under age 8 in families with income up to $100 \%$ of poverty line.

Effective July 1989, states required to cover pregnant women and children under age 2 with incomes up to $75 \%$ of the poverty line.

Effective April 1990, states required to cover pregnant women and children under age 6 up to $133 \%$ of the poverty line; given option to extend coverage to $185 \%$.

Effective July 1991, states required to begin phasing in coverage for all children under age 19 up to $100 \%$ of the poverty line. 
Figure 1. Medicaid Eligibility Thresholds and Fraction of Women Eligible via Expansions, 1982-1996

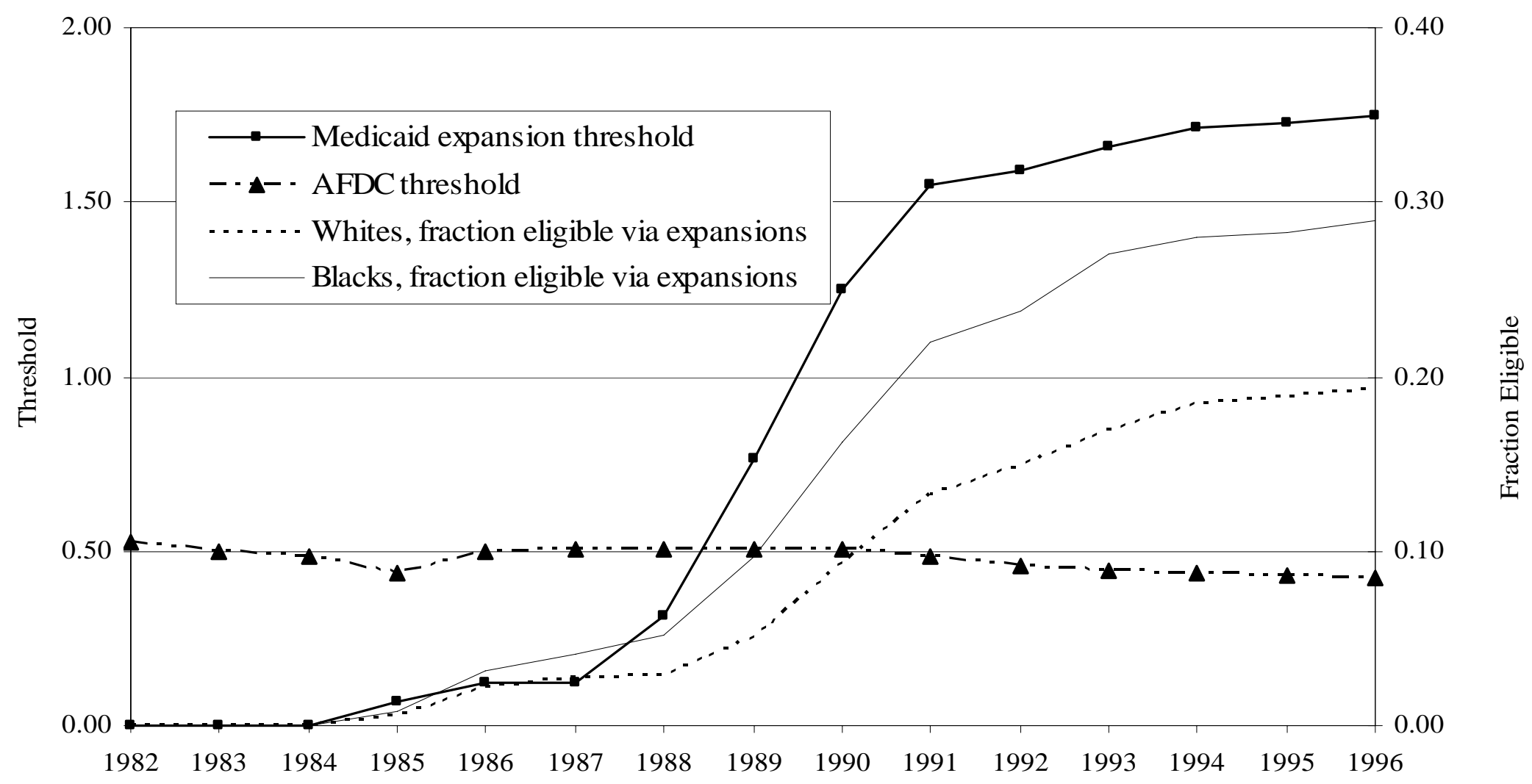

Note: The Medicaid expansions threshold is the average eligibility threshold across states, relative to the federal poverty level, weighted using the population of women aged 15-44, associated with the eligibility expansions that began in 1984. The AFDC threshold is the average eligibility threshold for obtaining AFDC benefits, which include Medicaid coverage. The fraction of women eligible is the fraction of women aged 16-44 from the 1983-1997 March Current Population Survey who would meet their state's income eligibility rules for the Medicaid expansion (does not include Medicaid coverage under the AFDC program). 
Table 2. Determinants of Birth Rates, including Medicaid Expansions Eligibility Threshold, by Demographic Group, 19821996

\begin{tabular}{|c|c|c|c|c|c|c|}
\hline & All & Unmarried & Married & $\begin{array}{l}<12 \text { years } \\
\text { education }\end{array}$ & $\begin{array}{c}12 \text { years } \\
\text { education }\end{array}$ & $\begin{array}{l}>12 \text { years } \\
\text { education }\end{array}$ \\
\hline \multicolumn{7}{|l|}{ Whites } \\
\hline \multirow[t]{2}{*}{ Expanded Medicaid eligibility threshold } & $.009 *$ & .027 & .009 & $.077 *$ & -.016 & -.004 \\
\hline & $(.004)$ & $(.024)$ & $(.010)$ & $(.035)$ & $(.019)$ & $(.014)$ \\
\hline \multirow[t]{2}{*}{ Ln(real AFDC benefits) } & .108 & .349 & .047 & .211 & $.127 *$ & -.070 \\
\hline & $(.056)$ & $(.180)$ & $(.036)$ & $(.127)$ & $(.090)$ & $(.150)$ \\
\hline \multirow[t]{2}{*}{ Ln(real per capita income) } & $.449 * *$ & .721 & $.363 *$ & .322 & $.462 *$ & $.409 * *$ \\
\hline & $(.093)$ & $(.394)$ & $(.142)$ & $(.345)$ & $(.181)$ & $(.164)$ \\
\hline \multirow[t]{2}{*}{ Unemployment rate } & .001 & .009 & .001 & -.011 & .005 & .001 \\
\hline & $(.001)$ & $(.006)$ & $(.002)$ & $(.007)$ & $(.004)$ & $(.004)$ \\
\hline \multirow[t]{2}{*}{ Ln(real EITC) } & -.022 & -.025 & $-.091 *$ & .123 & .004 & .038 \\
\hline & $(.040)$ & $(.146)$ & $(.038)$ & $(.109)$ & $(.059)$ & $(.070)$ \\
\hline \multirow[t]{2}{*}{ Medicaid abortion funding restriction } & .007 & .080 & -.028 & .032 & .006 & .028 \\
\hline & $(.011)$ & $(.055)$ & $(.016)$ & $(.049)$ & $(.027)$ & $(.028)$ \\
\hline \multicolumn{7}{|l|}{ Blacks } \\
\hline \multirow[t]{2}{*}{ Expanded Medicaid eligibility threshold } & .003 & .033 & -.040 & .059 & -.027 & -.040 \\
\hline & $(.011)$ & $(.018)$ & $(.022)$ & $(.036)$ & $(.038)$ & $(.050)$ \\
\hline \multirow[t]{2}{*}{ Ln(real AFDC benefits) } & $.102 * *$ & -.009 & $.339 * *$ & .032 & .031 & .162 \\
\hline & $(.036)$ & $(.085)$ & $(.100)$ & $(.234)$ & $(.242)$ & $(.216)$ \\
\hline \multirow[t]{2}{*}{ Ln(real per capita income) } & .231 & $.451 *$ & -.102 & .505 & .495 & -.226 \\
\hline & $(.129)$ & $(.224)$ & $(.442)$ & $(.587$ & $(.439)$ & $(.458)$ \\
\hline \multirow[t]{2}{*}{ Unemployment rate } & .003 & .004 & .005 & .004 & .0001 & .013 \\
\hline & $(.003)$ & $(.006)$ & $(.009)$ & $(.014)$ & $(.008)$ & $(.010)$ \\
\hline \multirow[t]{2}{*}{ Ln(real EITC) } & .097 & .055 & .110 & .127 & $-.443 * *$ & .295 \\
\hline & $(.119)$ & $(.136)$ & $(.181)$ & $(.253)$ & $(.156)$ & $(.211)$ \\
\hline \multirow[t]{2}{*}{ Medicaid abortion funding restriction } & $.077 * *$ & $.137 * *$ & -.056 & .162 & $.099 * *$ & -.019 \\
\hline & $(.025)$ & $(.031)$ & $(.053)$ & $(.100)$ & $(.037)$ & $(.055)$ \\
\hline
\end{tabular}

$* \mathrm{p}<.05 ; * * \mathrm{p}<.01$.

Note: The dependent variable is the log of the annualized number of births per 1000 women in the relevant group each quarter during 1982-1996. Robust standard errors clustered at the state level are in parentheses. Regressions include state and time fixed effects and linear state-specific time trends. 
Table 3. Determinants of Birth Rates, including Fraction of Women Eligible for Medicaid because of Expansions, by Demographic Group, 1982-1996

\begin{tabular}{|c|c|c|c|c|c|c|}
\hline & All & Unmarried & Married & $\begin{array}{l}<12 \text { years } \\
\text { education }\end{array}$ & $\begin{array}{l}12 \text { years } \\
\text { education }\end{array}$ & $\begin{array}{l}>12 \text { years } \\
\text { education }\end{array}$ \\
\hline \multicolumn{7}{|l|}{ Whites } \\
\hline \multirow[t]{2}{*}{ Fraction of women eligible } & .079 & .059 & .141 & .313 & -.138 & -.062 \\
\hline & $(.060)$ & $(.336)$ & (.069) & $(.258)$ & $(.197)$ & $(.300)$ \\
\hline \multirow[t]{2}{*}{ Ln(real AFDC benefits) } & .109 & .350 & .049 & .227 & .123 & -.071 \\
\hline & $(.055)$ & $(.177)$ & $(.035)$ & $(.129)$ & $(.089)$ & $(.151)$ \\
\hline \multirow[t]{2}{*}{ Ln(real per capita income) } & $.454^{* *}$ & .752 & $.364^{* *}$ & .365 & $.436 *$ & $.402 *$ \\
\hline & $(.090)$ & $(.396)$ & $(.141)$ & $(.341)$ & $(.182)$ & $(.168)$ \\
\hline \multirow[t]{2}{*}{ Unemployment rate } & .001 & .010 & .001 & -.011 & .005 & .001 \\
\hline & $(.001)$ & $(.006)$ & $(.002)$ & $(.007)$ & $(.004)$ & $(.004)$ \\
\hline \multirow[t]{2}{*}{ Ln(real EITC) } & -.016 & -.009 & -.085 & .169 & -.002 & .037 \\
\hline & $(.040)$ & $(.143)$ & $(.038)$ & (.109) & $(.057)$ & $(.068)$ \\
\hline \multirow[t]{2}{*}{ Medicaid abortion funding restriction } & .009 & .083 & -.027 & .030 & .004 & .027 \\
\hline & $(.011)$ & $(.057)$ & $(.015)$ & $(.049)$ & $(.026)$ & $(.029)$ \\
\hline \multicolumn{7}{|l|}{ Blacks } \\
\hline \multirow[t]{2}{*}{ Fraction of women eligible } & -.010 & .063 & -.269 & .060 & -.277 & -.149 \\
\hline & $(.101)$ & $(.123)$ & $(.230)$ & $(.318)$ & $(.226)$ & $(.490)$ \\
\hline \multirow[t]{2}{*}{ Ln(real AFDC benefits) } & $.102 * *$ & -.005 & $.331^{* *}$ & .052 & .023 & .149 \\
\hline & $(.037)$ & $(.084)$ & $(.099)$ & $(.236)$ & $(.240)$ & $(.226)$ \\
\hline \multirow[t]{2}{*}{ Ln(real per capita income) } & .238 & $.492 * *$ & -.129 & .564 & .462 & -.258 \\
\hline & $(.130)$ & $(.238)$ & $(.467)$ & $(.602)$ & $(.429)$ & $(.471)$ \\
\hline \multirow[t]{2}{*}{ Unemployment rate } & .003 & .005 & .005 & .005 & .0002 & .012 \\
\hline & $(.003)$ & $(.006)$ & $(.009)$ & $(.014)$ & $(.008)$ & $(.010)$ \\
\hline \multirow[t]{2}{*}{ Ln(real EITC) } & $.099 * *$ & .078 & .077 & .169 & $-.448 * *$ & .269 \\
\hline & $(.120)$ & $(.129)$ & $(.191)$ & $(.254)$ & $(.146)$ & (.199) \\
\hline \multirow[t]{2}{*}{ Medicaid abortion funding restriction } & $.077 * *$ & $.141^{* *}$ & -.065 & .170 & $.095 *$ & -.022 \\
\hline & $(.026)$ & $(.035)$ & $(.052)$ & $(.099)$ & $(.037)$ & $(.054)$ \\
\hline
\end{tabular}

$* \mathrm{p}<.05 ; * * \mathrm{p}<.01$.

Note: The dependent variable is the log of the annualized number of births per 1000 women in the relevant group each quarter during 1982-1996. Robust, clustered standard errors are in parentheses. Regressions include state and time fixed effects and linear state-specific time trends. 
Table 4. Determinants of Abortion Rates, by Data Source, 1982-1996

\begin{tabular}{|c|c|c|c|}
\hline & $\begin{array}{l}\text { CDC data, } \\
\text { all years }\end{array}$ & AGI data & $\begin{array}{l}\text { CDC data, } \\
\text { AGI years }\end{array}$ \\
\hline \multicolumn{4}{|l|}{ A. Expansion threshold } \\
\hline Expanded Medicaid eligibility threshold & $\begin{array}{l}.012 \\
(.040)\end{array}$ & $\begin{array}{c}.026 \\
(.022)\end{array}$ & $\begin{array}{c}.040 \\
(.050)\end{array}$ \\
\hline Ln(real AFDC benefits) & $\begin{array}{l}.180 \\
(.145)\end{array}$ & $\begin{array}{l}-.068 \\
(.152)\end{array}$ & $\begin{array}{l}.151 \\
(.170)\end{array}$ \\
\hline Ln(real per capita income) & $\begin{array}{l}.524^{*} \\
(.247)\end{array}$ & $\begin{array}{l}.634 \\
(.423)\end{array}$ & $\begin{array}{l}1.330 * * \\
(.357)\end{array}$ \\
\hline Unemployment rate & $\begin{array}{l}-.011 \\
(.009)\end{array}$ & $\begin{array}{l}.008 \\
(.007)\end{array}$ & $\begin{array}{l}-.001 \\
(.007)\end{array}$ \\
\hline Ln(real EITC) & $\begin{array}{l}.019 \\
(.120)\end{array}$ & $\begin{array}{l}-.103 \\
(.087)\end{array}$ & $\begin{array}{l}.075 \\
(.141)\end{array}$ \\
\hline Medicaid abortion funding restriction & $\begin{array}{l}-.087^{*} \\
(.043)\end{array}$ & $\begin{array}{l}-.069 * \\
(.031)\end{array}$ & $\begin{array}{l}-.119 \\
(.064)\end{array}$ \\
\hline B. Fraction of women eligible & & & \\
\hline Fraction of women eligible for Medicaid & $\begin{array}{l}.055 \\
(.255)\end{array}$ & $\begin{array}{l}.187 \\
(.358)\end{array}$ & $\begin{array}{l}-.100 \\
(.391)\end{array}$ \\
\hline Ln(real AFDC benefits) & $\begin{array}{l}.185 \\
(.141)\end{array}$ & $\begin{array}{l}-.056 \\
(.149)\end{array}$ & $\begin{array}{l}.157 \\
(.166)\end{array}$ \\
\hline Ln(real per capita income) & $\begin{array}{l}.530 * \\
(.242)\end{array}$ & $\begin{array}{l}.643 \\
(.431)\end{array}$ & $\begin{array}{l}1.354 * * \\
(.346)\end{array}$ \\
\hline Unemployment rate & $\begin{array}{l}-.011 \\
(.009)\end{array}$ & $\begin{array}{l}.008 \\
(.007)\end{array}$ & $\begin{array}{c}.0004 \\
(.008)\end{array}$ \\
\hline Ln(real EITC) & $\begin{array}{l}.027 \\
(.128)\end{array}$ & $\begin{array}{l}-.080 \\
(.098)\end{array}$ & $\begin{array}{l}.090 \\
(.151)\end{array}$ \\
\hline Medicaid abortion funding restriction & $\begin{array}{l}-.086 \\
(.044)\end{array}$ & $\begin{array}{l}-.067^{*} \\
(.031)\end{array}$ & $\begin{array}{l}-.119 \\
(.063)\end{array}$ \\
\hline
\end{tabular}

$* \mathrm{p}<.05 ; * * \mathrm{p}<.01$

Note: The dependent variable is the log of the annual number of abortions per 1000 women aged 15-44. In column 1, the CDC sample covers all years 19821996; in columns 2 and 3, the AGI and CDC samples cover the years 1982-1996 except 1983, 1986, 1989, 1990, 1993 and 1994. Robust, clustered standard errors are in parentheses. Regressions include state and time fixed effects and linear state-specific time trends. 